Cognitive and Affective Scarcities and Relational Abundance: Lessons From The Confluence of Extreme and Chronic Scarcities in Subsistence Marketplaces

\title{
MADHUBALAN VISWANATHAN
}

ASHOK K. LALWANI*

Madhubalan Viswanathan (marketplaceliteracy@gmail.com) is Professor of Marketing at the Department of Marketing, College of Business Administration, Loyola Marymount University, 1, LMU Drive, Los Angeles, CA90045, and Ashok K. Lalwani (lalwani@indiana.edu) is an Associate Professor in the Department of Marketing, Kelley School of Business, Indiana University, 1309 E. $10^{\text {th }}$. St., Bloomington, IN, 


\begin{abstract}
Research on subsistence marketplaces provides a number of insights about extreme and chronic resource scarcity as well as intangible scarcities in cognitive and affective realms. These insights have been developed from a variety of sources - quantitative and qualitative research, as well as education for communities and for students through a symbiotic academic-social enterprise. These insights are juxtaposed with extant work on scarcity in consumer research, to derive implications for future research and stimulate thinking on a broad variety of scarcities. Our holistic deep dive into extreme scarcity and its multiple dimension from the perspective of consumer behavior has much to offer in stimulating future research on scarcity.
\end{abstract}


"I never thought of myself as customer, just as someone who buys from the shopkeeper who sells" - participant at the end of a marketplace literacy program in South India.

A large percentage of the world's population lives with low income and extreme and chronic scarcity ${ }^{1}$. However, the bulk of our understanding of consumer behavior comes from relatively resource-rich settings. The differences are stark globally as well as locally. Consider a typical shopping trip that we make. We consider a few brands and variations of a few items, trade-off a few attributes, fill our shopping baskets, and head for the counter. If we want cash transactions but are short of money, we set aside some items and move on, not giving much thought to our forgetfulness. This daily shopping event reflects an abundance of not only products and tangible resources, but of intangible cognitive and affective resources as well.

Now consider an example reflecting a composite of low-literate, low-income consumers shopping in the US. Finding a product may be difficult if reading signs is challenging. The option of asking an employee for help is not always readily available, or easy to do from the perspective of maintaining self-esteem. With all the effort to find a product, the first one found may be picked up without performing any trade-offs or evaluations. Finding multiple combinations of volume may take effort (say, if 60 pencils are needed and therefore, packets of smaller sizes (36 and 12) have to be located). Determining the actual price to be paid may be difficult when there are many different prices and discounts, not to mention coupons (Lalwani and Monroe 2005). In fact, percentage off signs may be a deterrent when computing the final price does not come easily, and consumers may consequently forego steep discounts, such as 70\% off (Quote). Similarly, computing the prices of multiple units may take effort. For example, if one costs $\$ 2.50$, then what two or three will cost may require the use of a calculator. Unit

\footnotetext{
${ }^{1}$ Extreme scarcity that is not chronic may occur outside low-income settings such as in disaster zones.
} 
prices being abstractions derived from price and size, are difficult to comprehend, with each element being confusing in its own right (e.g., size involves unit of measurement). Computing the approximate cost of the shopping basket and ensuring it is within the available budget is not trivial. Estimating budget amounts remaining after each purchase can involve multiple computations (e.g., spending 2-3 dollars on one item and assessing what remains in a $\$ 50$ budget for 5-6 items). And finally, sufficient money at the counter can be a source of relief, and being short, a source of embarrassment, even despair. The attribution may be to one's own low literacy, which, in turn, is the perceived cause of low income and a life of hardships due to material resource constraints. Faced with these challenges, people try to adapt, ordering one item at a time from a menu to avoid running out of money, keeping a limited amount of money on their person, seeking out stores with employees who know their constraints and are helpful, or even completely depending on relatives or friends to help them shop (Viswanathan, Rosa, and Harris 2005).

A number of intangible scarcities are inherent in these examples relating to cognitive, affective, and behavioral aspects of low-literate, low-income consumers in an advanced economy, the US. They represent one end of the spectrum of low income in the study of subsistence marketplaces, which extend to relatively lower income consumers in contexts of widespread and more extreme poverty. The example also captures our orientation of unpacking the broad range of low income in terms of the highly associated low literacy, a unique foundational characteristic of our approach to examine the material with the cognitive and affective. $^{2}$

\footnotetext{
${ }^{2}$ We acknowledge the many factors that are associated with low income around the world, be it ethnicity, or rural location. We take a bottom-up and holistic approach recognizing the distinctiveness of each context, hence the qualitative term, subsistence, rather than distinctions such as dollars a day based purely on income. Low literacy is
} 
The hypothetical customer depicted in the introductory example lives in a setting with much exposure to stores in a relatively advanced economy with significant pockets of poverty. Consider now a customer in settings of more wide-spread poverty - urban, semi-urban, rural, or isolated tribal. In a rural setting, there may be a few small (often makeshift) shops in a village to buy from. Indeed, social hierarchy and filial ties may lead people to buy regularly in just one of those few shops. The hub town market with many shops may be many miles away, often beyond reach certainly on a regular basis and require overcoming cognitive (knowledge and skills), and affective (self-confidence) scarcities to reach and transact at. With exposure very limited, and lack of literacy to learn about what is out there, a low income customer may have a limited vantage point - go to a shop, ask for what is needed - basic necessities usually, and pay for it evaluating "options" and making a choice being luxuries beyond reach. Even the notion of buying has to be weighed against making or foregoing with very limited affordability. The product range is very limited and quality among the lowest. The shopkeeper adds value by transporting the products to the proximity of the "customers" from hub towns with larger markets. Indeed, this is not even the most extreme of customer circumstances we have studied. Isolated tribal communities travel tens of miles to a Saturday marketplace near the main road, a once-a-week event where they buy and sell from small, make-shift shops. The very exposure, choices and information that we take for granted in being and understanding "customers", indeed the word itself and the concept underlying it, is called into question in these settings. In turn, developing the cognitive, affective and behavioral elements of being an effective customer are far beyond reach. Yet, exchange is happening and remains at the heart of everyday living.

distinct as a factor though in how it translates across contexts in its relationship with income and is central to consumer behavior as we demonstrate in this paper. 
Indeed, with extreme resource constraints, each decision remains vitally important with little margin for error.

In this paper, our experience in working in subsistence marketplaces (Viswanathan and Rosa 2007) and learning about extreme resource scarcity as well as intangible scarcities in cognitive and affective realms is juxtaposed on extant research on product scarcity developed in consumer research. Ours is a deep dive into phenomena for its own sake rather than a theoretical step forward from research on higher-income customers. We acknowledge the pioneering work in extreme scarcity settings that precedes ours (e.g., Andreasen 1975; Arnould 1989; Hill 1989; Alwitt and Donley 1996). Rather than an exhaustive review, the aim here is to stimulate thinking on a broad variety of scarcities. Our insights are drawn from a variety of sources - quantitative and qualitative research, courses for thousands of students on-campus and online, sometimes involving field research, and educational programs on marketplace literacy that have reached 100,000 individuals in seven countries (www.marketplaceliteracy.org). Our approach of symbiotic academic-social enterprise has important methodological implications for researching extreme scarcity.

Unique to the subsistence marketplaces approach compared to macroeconomic or bottom-of-the-pyramid approaches is grounding in micro-level insights and a bottom-up orientation to derive implications for product development, business models, and sustainable development (Viswanathan 2013). 'Subsistence' consumers refers to those with low income, barely making ends meet. Marketplaces rather than markets denotes an orientation of capturing associated life circumstances beyond income, primary among them being lower levels of literacy. At an affective level, life circumstances bring a host of issues, such as lack of selfesteem in shopping encounters. Subsistence marketplaces in their own right represent a complex 
combination of scarcities at extreme levels. We juxtapose our insights with recent consumer behavior literature on scarcity, summarized in figures 1 and 2.

Insert figures 1 and 2 here

\section{Extreme and Chronic Scarcities in Subsistence Marketplaces}

Our approach to unpacking poverty is summarized with first impressions. Observing a group of low-literate, low-income consumers shopping more than two decades ago, reflected in the earlier example from the US, left one strong impression - the things we (who are relatively resource-rich) take for granted. Today, that story is much more nuanced - the things we take for granted are not just material, they relate to thinking, feeling, and doing/coping - the cognitive, affective, and behavioral, and extend beyond the tangible or quantifiable.

Our observations uncovered how resource-poor consumers spend so much time on even rudimentary tasks, such as finding a product in a store, computing prices of multiple units, computing final price based on sales discounts, etc. Inability to read means that much effort is spent in just locating a product, which leaves limited resources for the various stages of purchase and experience. Indeed, sometimes the model that best fits appears to be one of find it - buy it, in light of considerable effort expended in getting to that point (Viswanathan 2012). Extreme resource scarcity leads to a broader "choice" of buying, making, or foregoing, individuals having resilience to do the latter (Viswanathan et al. 2009). Making in some instances has a number of advantages outside of affordability, such as the ability to customize for different family members.

\section{Defining Characteristics}


Two defining characteristics of subsistence marketplaces are uncertainty in different realms of life and lack of margin of error (Viswanathan 2013). A typical day at the top of the income pyramid is filled with certainties. Moreover, there is a cushion, a margin of error, due to infrastructure, institutional mechanisms, financial assets or an array of options that resources afford. In subsistence marketplaces, uncertainties relate to the most basic of day-to-day consumption activities in various domains (e.g., availability of food or water). Uncertainty relates to whether extreme scarcity will be alleviated and margin of error pertains to the harsh downside when it persists. A confluence of extreme scarcities are overlaid with uncertainties about the states of scarcities and very little by way of cushion or surplus. Uncertainty and margin of error are germane to all forms of scarcities - observable (e.g., product scarcity and resource scarcity) as well as intangible, the latter emphasized here in thinking and feeling. We distinguish between level and uncertainty of resources, even though they are often related. Scarcity refers to "having less than you feel you need" (Mullainathan and Shafir 2013), whereas uncertainty refers to the variability of the level of those resources. For example, Mittal and Griskevicious (2014) found that uncertainty reduced the sense of control (and consequently, increased impulsive behavior) of people from poorer (versus wealthier) childhoods significantly more, leading them quit challenging tasks sooner. Next, we discuss scarcities relating to the cognitive and the affective as well as abundance in the relational realm.

\section{Cognitive Scarcity}

Cognitive scarcity arises from lack of material resources as well as associated lack of literacy and exposure. A unique consequence from our work is concrete thinking arising from difficulty with abstractions (Viswanathan et al. 2005; 2018). "I buy the cheapest" is a common refrain even when the more expensive volume is a much better deal. This is not only because of 
lack of income (and affordability) but because of cognitive scarcity and concrete thinking. It manifests in difficulty combining pieces of information to form a more abstract judgment - say of price and other dimensions such as size to arrive at a notion of value, or distance and costs to trade off where to purchase (Viswanathan 2013; see also Lalwani and Shavitt 2009; 2013;

Lalwani and Forcum 2016). The quote below from Viswanathan et al. (2005) illustrates concrete thinking.

“. I I look to see which costs the most and which costs the less, and so I just get the smaller one because they cost the less."

Interviewer - “..let's say you buy a packet of bread that's half the size . . you are getting less bread for the money. How do you try to make sure it's cheapest in terms of how much you are getting also?

"I just look at the tag and see what's cheapest. I don't look by their sizes."

Buying the cheapest arises not only due to resource scarcity but due to cognitive constraints, such as in abstracting across price and size. Luria (1931) showed how low-literate peasants in Central Asia responded when asked for a word to describe objects such as a hammer and an axe. Rather than "tools," they responded in how they would use a specific object to cut a tree and get firewood and keep their families warm. Thus, low literacy leads to difficulty with abstractions and living and thinking in the immediate, visual, graphic, sensory, world of here and now and how something can be used. Distinctly different from material resource constraints alone, cognitive resource constraints relates to fundamental constraints due to lack of literacy. Scarcity in the cognitive arena relates to difficulty combining pieces of information to make a judgement and consequent emphasis on one or a few attributes (though it may manifest in other ways as well). 
Many of the words we use to denote concepts, be it customer, enterprise, or interest rates, unit price, healthiness, or nutrition presume the ability to abstract. Even the notion of a customer can be formed at a very rudimentary level, translating, for instance, to going through the motions of buying from a single small shop as a buyer rather than a customer. The quote at the beginning of the paper is poignant feedback from a participant. Broad principles of competition are often beyond the realm of understanding, whereas fair exchange at a human level is more clearly understood. Higher levels of abstraction relating to metacognition and deciding how to decide are even more difficult to process.

Relating concepts through causality is another aspect where there is what we refer to as "flat causality." Relating abstractions to each other is difficult for the poor and low-literate, and all the more so, hierarchical causality spanning different levels of abstraction. Consider the domain of health where a variety of indicators lead to probabilities of conditions occurring - "I had this symptom but now it is gone" when indeed the underlying condition is quite serious. For subsistence consumers, the human-healthcare interface is particularly complex due to hierarchical causality and abstract thinking (Viswanathan et al. 2018). Consider assessing cause and effect in the marketplace (e.g., the notion of value in an exchange) or a customer orientation leading to more marketplace opportunities as an entrepreneur. Consider trading off immediate gratification with reward down the road. We have referred to the notion of abstract-concrete fluency in this regard (Viswanathan 2017). In other words, the levels of abstraction may be constrained as may be the fluency of moving across different levels of abstraction. If there are constraints to understanding abstract concepts, then relating them in some causal fashion involve another level of difficulty. Meta-decision-making or deciding how to decide is, as well, in the domain of the very abstract (Viswanathan et al. 2005). 
Extreme scarcity in the material resource domain interacts with the cognitive. Indeed, uncertainty and lack of margin of error call into question causal beliefs in a relatively resourcerich world. Randomness of events in day-to-day life breaks down such causal beliefs or may prevent them from forming to begin with. "If one works hard, there is a reward", is a reasonable causal belief in a resource-rich world filled with certainties. But it is put to test in contexts of inherent uncertainty where random events are pervasive.

Narrowing is generically spoken of scarcity research (Hamilton et al. 2019). We find such narrowing to specifically be toward the more concrete and transactional attributes needed to function, such as the lowest price, or the biggest package size if much distance has to be travelled to the marketplace (Viswanathan 2013). Narrowing is a generic observation of low income that resonates with our work. However, we explicate the consequences of low literacy, low income and lack of exposure with the notion of concrete thinking and its different manifestations in relation to different facets of abstract thinking (e.g., flat causality) as we do the notion of pictographic thinking and dependence on sensory-first principles below (Viswanathan 2005).

Another cognitive predilection we have found in both qualitative and quantitative research is pictographic thinking (Viswanathan et al. 2005), essentially relying on available sensory information irrespective of literacy level. Not merely a dependence on pictures, this is a different way of processing - "I do sight reading" is a representative sentiment here. Be it a pattern matching numbers of buses or first letters of prescriptions, viewing brand names as images rather than words, visualizing amounts to buy rather than using units of measurement, and even computing a shopping basket pictographically by visualizing dollar bills. The quote below from Viswanathan et al. (2005) illustrates pictographic thinking. 
"When you go back to the store, you look and see oh, this is the brand I bought before - I ain't gonna get this, I'm gonna get that other one."

Interviewer - How do you tell that it's the brand you bought before?

"Ain't nothing wrong with my eyes."

Memory differences within levels of low to moderate literacy associated with brand names have been found to be nullified when using familiar brand signatures (Viswanathan et al., 2009). Dependence on the pictographic, or broadly the sensory, to bypass literacy requirements, is a tendency in the cognitive realm. These insights can also be reinterpreted through the lens of psychological distance of construal level theory (Lalwani and Wang 2019; Trope and Liberman 2010). Larger spatial distances are difficult to envision in extreme scarcity due to lack of exposure, resources, or literacy, and consequent difficulty with abstraction. Social distance is compounded by affective issues relating to self-confidence and self-esteem (elaborated later). Temporal distances involve abstracting across time. Hypothetical distance involves a form of abstraction - for instance, envisioning buying in distant markets or evaluating hypothetical nutritious products.

In light of these cognitive predilections, we advanced the notion of cognitive survivors rather than cognitive misers (Viswanathan et al. 2005). Indeed, survival in a thinking sense occurs when resource scarcity is so compelling with limits to thinking due to low literacy.

\section{Affective Issues}

The earlier example indicates how mundane shopping events can be cause for relief or possibly despair. Indeed, consumers living in extreme and chronic resource scarcity experience a range of very negative emotions. These affective issues are deeply intertwined with cognitive issues. A simple illustration when we conduct poverty simulations is telling, wherein participants 
are assigned roles and 15 minutes represents a week in their lives. Even with this fleeting simulation of life circumstances, participants are most surprised at how anxious they were and how it affected their thinking. What then can be the effects of long-term resource scarcity? Specific to consumer behavior, lack of self-esteem and self-confidence in mundane shopping encounters may lead to economic value being traded off for being treated with respect (Viswanathan et al. 2005). Mundane activities, such as having sufficient money at the counter, take on larger meaning when the attribution is to one's own low income or low literacy and the associated stigma (Adkins and Ozanne 2005; Viswanathan et al. 2005). The affective element of lack of self-confidence in the marketplace represents another intangible scarcity. "How to make the purchases if I go to a shop? How to ask the seller? How much would they say (the price)?... If I had studied well, at least up to 8th standard (grade)... You see, sometimes they (larger shops) ask me what my educational qualification is. I feel bad. I wouldn't have such feeling if I had studied... I agonize about why I didn't study, about why my family didn't provide me the education .. ." - 28 year old woman, 3 rd grade education, South India.

Nowhere in our experience has the affective been more stark than in refugee settlements where people flee from a past of torture and unthinkable violence, yet caught in the present as hope for a better future seems so futile. Their affective state, in combination with cognitive and resource scarcity, can fixate them in the present, the interaction of these different elements under extreme circumstances. Like narrowing, focusing on the immediate is sometimes described as a characteristic of poverty. We unpack the underlying cognitive, affective, and material scarcities.

\section{Relational Abundance and 1-1 Interactional Marketplaces}

Another characteristic of subsistence marketplaces is relational abundance. There is an abundance that accompanies many scarcities, double-edged as it is - social or relational richness 
in subsistence marketplaces in many developing contexts, referred to as 1-1 interactional marketplaces (Viswanathan et al. 2012), perhaps far beyond what exists in resource-rich advanced economies. Greater monitoring of social environments manifests in more extreme ways in developing contexts. In fact, the social milieu blurs with the marketplace in these settings, an intertwined existence between the social and the individual (Viswanathan et al. 2009).

Such 1-1 interactions bypass low literacy, building on strengths people have irrespective of their low education and literacy. However, these social networks are double-edged as well, as they can lead to ostracism when people don't conform. The larger context has been described in terms of interdependence and oral communications. Exchanges can be fluid and responsive between small buyers and sellers, with constant requests or demands for customization. The relational environment is characterized by enduring relationships, multiplying the value of each small transaction, and interactive empathy, in conditions of shared adversity, between and among buyers and sellers. The quote below from a participant illustrates enduring relationships (see Viswanathan et al. 2012 for details).

"We will not change the shop. We will buy in a single shop. The things in this shop will be good. If there are any differences in the shop, we will return it to them. We will boldly go and ask as these things are not good and up to expectations. He will immediately change the ...For me, he will give the best goods after weighing. I would say "I am buying it from you continuously, how can you give me this?"...",

Social and economic blur in these 1-1 interactional settings, providing the stepping stone to develop consumer skills without depending on formal literacy and numeracy (Viswanathan et al. 
2009). Unique to the subsistence marketplaces stream is unpacking generic notions of social capital, providing more specific avenues for future research.

\section{Functional Literacy in the Marketplace}

Contexts of chronic scarcity differ but defy simple comparisons, each posing unique challenges for day-to-day living. Whereas poverty is more widespread and extreme in developing contexts, there can be relational richness as well. Ironically, our observations suggest that functional literacy in the marketplace is lower in more advanced (versus developing) economies with chronic resource scarcity. Marketplace interactions in advanced economies are with large chain stores, technology that computes, and an informational environment that assumes a certain level of literacy. Such contexts lack 1-1 interactions, the experience of being a seller oneself, counting currency in purchases, and learning among and between buyers and sellers to develop skills and alleviate cognitive or affective scarcities.

Our experience with an educational program we created based on our research is instructive. The notion of marketplace literacy came out of this work, encompassing knowledge and skills (cognitive), self-confidence (affective), and awareness of rights, for consumers and entrepreneurs (Viswanathan et al. 2008). The program emphasized the know-why, rather than the what or how, to address cognitive and affective constraints. The program was fundamentally bottom-up, stitching together concepts such as value in an exchange from people's lived experiences rather than convey them top-down. The program concretizes, localizes, and socializes the education, the latter building on the abundance of relational richness and the ability of those with cognitive scarcity due to low literacy to engage in social relations like anyone else, perhaps better. Preliminary evidence shows how such education impacts abstract thinking about the marketplace. 
Our research also identifies coping strategies such as problem-focused (order one item at a time from a menu) to emotion-focused (decreasing stress), avoidance oriented (avoiding drivethrough) to confronting (asking for help). Quotes from Viswanathan et al. (2005) illustrate coping.

"No, I don't do too much stuff, my daughter do all the shopping .. . when I am a daughter ... my mom did a lot of shopping." - A 60 year old woman in the US:

"I was reading the label on the polish sausage, trying to see what kinds was they... [but before I could read:] I just had to ask somebody, "what this say? You know I can't see man, can you help me out? I need glasses." I play it off like that, that's how I used to do it."

These strategies can be before or after a purchase decision (Viswanathan et al. 2005). They stem from the scarcities described in terms of the material, the cognitive, and the affective.

We have also examined what individuals living in extreme scarcity sustain, bottom-up, such as surviving, relating (to others and the environment), and growing (for themselves or the next generation) (Viswanathan et al. 2014). This stream of research has also examined chronic versus periodic consumption constraints or resource scarcity (Venugopal, Viswanathan, and Jung 2015). Chronic extreme scarcity can also have variations such as during the end of the month or during different stages of the agricultural cycle, which are periodic in nature.

The methods used to conduct such research in challenging settings can best be described as bottom-up and a symbiotic academic-social enterprise. Field teams in several countries have been dedicated to sustained research efforts, and the challenges involved documented elsewhere (Viswanathan 2011). However, these methods are noteworthy as they call for a platform that enable scholars to conduct research spanning the full spectrum of different types of scarcities.

\section{Juxtaposition With Scarcity Research and Future Research Pathways}


Next, we juxtapose insights from subsistence marketplaces with extant work on scarcity, with a discussion of each stage in the consumer journey.

\section{Need/Problem Recognition}

Much consumer research has focused on the important first step in the consumer journey of need or problem recognition. Consumer needs cannot be viewed in isolation from larger life circumstances (Pitta, Subrahmanyan, and Gomez- Arias 2008). In extreme material resource scarcity and relational abundance, needs can blur with the community and the larger context in subsistence marketplaces. We reiterate that material resource scarcity goes beyond the purchasing option to making or foregoing (Viswanathan et al. 2009). Recognizing a need or problem is distinct from having it rise to the level where it can be considered beyond foregoing. We also note basic as well as aspirational needs, the latter both relating to brand and life aspirations. For example, education as a pathway to a better life for the next generation is one powerful life aspiration. The immediacy of basic needs and material resource scarcity may also lead to bypassing many steps in the consumer journey to purchase behavior and consumption.

\section{Information Processing and Consideration of Alternatives}

By the time consumers with scarce resources reach the information processing and consideration of alternatives stage, they may have already expended considerable effort and time. What happens prior to this initial processing is another area ripe for future research. Having expended considerable effort on what precedes and is taken for granted by resource-rich consumers, consumers in extreme scarcity may spend time on one or two key dimensions, such as price or size, narrowing the initial consideration of both attributes and alternatives. Considering product scarcity and how initial motivation to process affects elaboration, interesting examples such as of a countdown of product items left in an online shopping 
environment have been used to illustrate these effects (Hamilton et al. 2019). The parallel is realtime countdown on a variety of essentials with extreme scarcity. Whereas arousal due to scarcity can reduce cognitive capacity, initial motivation to process information can be a moderator. However, motivation to process information needs to be distinguished from motivation to alleviate the scarcity; the latter sometimes being in tension with the former. This can arise as a result of the cognitive and the material being in concert, due to low literacy and low income, leading to a fixation on the here and now (Viswanathan et al. 2018). Abstracting across time as well as inferring causal relationships of a hypothetical nature all represent larger psychological distances in construal level theory. Indeed, this fixation on the immediate present can also arise due to extreme emotional circumstances, as in refugee camps where individuals escape from a dreadful past with little hope of a promising future. Thus, the affective can also act in concert with the cognitive and the material. Coping behaviors also evolve and are often rudimentary in nature, such as buying habitually, further narrowing the level of information processing. Finally, relational abundance and trust in the shopkeeper may alleviate the need for both information processing and consideration of alternatives. Research should examine how scarcities that are quantifiable interact with those that are not, such as the cognitive or the affective, at different levels of the continua.

Future research should examine the interplay between different types of scarcities, both tangible and intangible, at extreme and moderate levels. Such insights at the extremes can inform effects of moderate levels of types of scarcity, when translating to higher-income segments. Moreover, the motivation to process information can also be examined in concert with other motivations. Levels of literacy as a measured variable can moderate the results and serve as a proxy for scarcity in the thinking realm. Further, examining different levels of literacy crossed 
with income in a narrow range can create strong tests of hypotheses. Another moderator here is marketplace literacy and its elements such as knowledge and skills, and self-confidence. Future research should emphasize the intangibles in terms of cognitive and affective elements.

Greater emphasis on social environments for those with resource scarcity resonates with our research (Piff et al. 2012). At its extreme are 1-1 interactional marketplaces with pervasive interdependence and oral communications, fluid and responsive exchanges, and enduring relationships and interactional empathy. These findings provide pathways for future research in settings with moderate resource scarcity of a transient versus a more chronic nature. How does scarcity engender a relationship orientation, an interdependent mindset, interactional empathy, and so forth? For instance, the literature points to more giving among lower-income groups (Piff et al. 2010). How does moderate versus extreme resource scarcity affect relationship-building in the marketplace - a question with cognitive and affective implications?

Evaluation of opportunity costs in the face of resource scarcity and considering tradeoffs in terms of spending money (Shah et al. 2015) may be moderated by level of literacy level as well as resource scarcity. With compounding dimensions of extreme scarcity, opportunity cost as an abstraction tradeoffs across multiple dimensions may be difficult to factor. Subsistence consumers clearly understand their current lives and the lost opportunities due to changes, such as lost wages due to shopping at distant locations. But these are experience-based learnings coexisting with related negative feelings, differing from weighing opportunity costs abstractly when considering different hypotheticals. Both trading off different elements and imagining a scenario of not buying something are at increased psychological distances. Lack of transportation arising out of scarcity can also reduce consideration of options (e.g., Fortney and Booth 2002; Sharkey 2009). With more chronic resource scarcity, lack of exposure limits the options that 
consumers are even aware of. Thus, whereas lack of resources may suggest being thoughtful, lack of exposure and lack of literacy-related cognitive or thinking-related elements may suggest the opposite. Survival is not only in the material but in a sense, in the cognitive and affective as well, hence our notion of cognitive survivors.

\section{Evaluation of Alternatives}

In terms of evaluation of alternatives, reason(s) behind product scarcity have been noted as driving effects - such as exclusivity versus popularity (Hamilton et al. 2019; Wu and Lee 2016). In contrast, in extreme and chronic scarcity compounded with cognitive and affective scarcities, attribution may be to the self and one's own life circumstances rather than anything external, as scarcity is the state of affairs and resignation and acceptance are common responses. Even here, the distinction between those moderately-literate versus low-literate, while having chronic resource scarcity is germane in terms of how passive those with low literacy can be and how much they may attribute to the self versus the external (Viswanathan 2013). Thus, low literacy can have both cognitive and affective impacts, and marketplace literacy, which encompasses both, may be an important moderator. Research should examine related questions about moderating effects of product scarcity as well as literacy and marketplace literacy, and processes in terms of cognitive and affective mediators.

Resource scarcity is argued to lead to more focus on lasting utility (Tully et al. 2015).

With more extreme resource scarcity compounded by scarcity related to cognitive capacity, careful consideration that abstracts across time or other dimensions may be difficult. However, lived experience is a harsh teacher as the necessity of meeting immediate basic needs leads to learning, particularly from poor decisions that, say, affect the next meal or the basic essentials. Thus, product trials and actual experience and associated negative affect when combined with 
the lack of margin of error and the need to make effective decisions can lead to effective learning, even if abstract reasons underlying behavior are not fully understood or articulated. Sadly, some of this learning can arise from crises, such as due to adverse health outcomes. A related point here is the dependence not so much on search attributes as on experience and credence attributes. In this regard, relational abundance can lead to trust in the seller as a primary driver that impacts the cognitive. Future research should examine the nature of product attributes that comparison are made on, as a function of types of scarcity. Similarly, the nature of learning about products in terms of trial versus search also needs to be studied. Here again, the role of literacy and more generally marketplace literacy as moderators need to be studied.

\section{Choice}

With choice, the effects of resource scarcity resonate with our findings. A key limitation in subsistence marketplaces is affordability as well as the limited options available. Because consumers who face scarcity tend to think in concrete (rather than abstract) terms (Viswanathan et al. 2005; 2018), they may perceive (and feel) that fewer options are available (over and above fewer availability of options, as in subsistence marketplaces). Hence, the effects of scarcity may be amplified in multiple ways - having less, perceiving less, and having negative feelings from having/perceiving less. Because perceiving less triggers the desire to acquire (Park, Lalwani, and Silvera 2020), an interesting research question is how having fewer resources interact with greater desire to possess more things. Do they lead to greater discontentment (compared to only due to having less) or cognitive dissonance? Moreover, factors that influence concrete versus abstract thinking are likely to moderate the effect of scarcity on perceptions of availability of products. Cognitive constraints, low literacy levels and low income levels create time pressures that discourage consumers from comparison shopping and/or utilizing promotions (Mittal 1994). 
These factors compounded with associated affect may further encourage suboptimal choices among consumers.

Another issue that consumers who experience scarcity need to decide is whether to make (if viable) or buy (if affordable) or forego (if neither viable to make and unaffordable) a product (Viswanathan et al. 2009). Often, such individuals opt to make an item, such as an ingredient in a food preparation, allowing for customization while being affordable. Alternatively, they may forego products because of resource constraints. Moreover, cognitive and affective scarcities may prevent consumers from either making or buying and increase the tendency to forego. One woman commented: "Chili powder is sold readymade. But I do not buy it. I buy Chili and Dhania (ingredients) and crush it to make chili powder. Sometimes packet products may not be fully usable. I crush even wheat to make wheat powder...." (Viswanathan et al. 2009). Further research is needed to understand the make or buy or forego option at a micro level at differing levels of scarcity.

Growing up with chronic resource constraints is also associated with risk-taking (Griskevicius et al. 2013). Does poverty mean nothing to lose or everything to lose (Viswanathan 2013)? What are the moderating factors that lead to possibly diametrically opposite risk perceptions in extreme resource scarcity? Within the range of moderate to extreme resource scarcity, what is the shape of this relationship? Does extreme resource scarcity mean preserving the little that people possess or risking it for more? What factors moderate and mediate this relationship? Similarly, the link between immediate gratification and growing up without certainty resonates with the difficulty with causal relationships and the development of causal beliefs discussed earlier. Future research should assess the nature of causal inferences drawn 
when intangible scarcities combine with chronic resource scarcity. Furthermore, the higher resilience of those with lower socio-economic status is very consistent with our findings.

\section{Consumption Experience}

Previous research suggests that poverty is characterized by consumption inadequacy and felt deprivation (Blocker et al. 2013, 1196). Indeed, the poor are aware of their deprived needs and able to identify the means to fulfill those needs, but unable to do so. Scarcity also triggers creativity in finding solutions to life's problems and needs (Hill 2001; Rosa, Geiger-Oneto, and Fajardo 2012), reinforcing the adage "necessity is the mother of all inventions". Scarcity activates a constraint mindset that manifests itself through reduced functional fixedness in subsequent product usage contexts, thereby enhancing product use creativity (Mehta and Zhu, 2016). Consumers who face scarcity come up with novel ideas on product usage, including using a product for multiple purposes (Viswanathan et al. 2009; Mehta and Zhu 2016; Rosa et al. 2012). Other research suggests that abstract (versus concrete) thinking increases creativity (Forster, Friedman, and Liberman 2004). However, scarcity increases concrete thinking (and reduces abstract thinking) (Viswanathan et al. 2005; 2018). Perhaps the constraints mindset path dominates the alternative path based on construal level (Mehta and Zhu 2016). Future research should explore boundary conditions when each path is active and identify situations when scarcity increases (versus decreases) creativity.

The notion of prolonging the consumption experience discussed in the scarcity literature (Hamilton et al. 2019) has parallel perhaps in having certain central consumption experiences, such as the primary meal or making and consuming purchases that celebrate the good times, however occasional they may be. Future research should examine how different types of consumption are experienced as a function of types and levels of scarcities. 


\section{Consumer Journey}

A number of issues relate to how the effects of types of scarcities in one stage of the consumer journey compare or contrast with other stages (Hamilton et al. 2019). In comparison, in extreme scarcities, each stage can blur into others and can be indistinguishable. Moreover, the overwhelming effects of extreme scarcities may carryover across two or more stages of the consumer journey. Future research should unpack the very nature of the consumer journey as well as how stages blur or are distinct as a function of the level and type of scarcity and the interplay between different types, and how effects hold up or differ across stages.

Disentangling degrees of scarcity is another important avenue for future research. For instance, Martin and Hill (2011) found that relatedness and autonomy improve poverty's negative influence on life satisfaction, but only if life's basic necessities are fulfilled. This finding adds nuance to research showing that connections to family and friends offset the negative effects of poverty (e.g., Baumeister and Leary 1995). Importantly, research is needed on the influence of mundane day-to-day material resources typically taken for granted in resourcerich settings, such as clean water, nutritious meals, and health care, i.e., domains of subsistence, on various facets of consumer behavior.

Scarcity is an aversive state that people are motivated to overcome (Park, Lalwani, and Silvera 2020). A route to do so, scarcity reduction, reduces the discrepancy between consumers current and desirable resource levels; increasing valuation of resources that are scarce (Shah, Mullainathan, and Shafir 2015), attempting to gain more money after losing it in a game (Sharma et al. 2014). Another route, control-restoration, reestablishes lowered personal control in other domains; increasing consumption of status or positional goods (Griskevicious et al. 2013), and foods high in calories (Briers and Laporte 2013; Laran and Salerno 2013). 
Cannon, Goldsmith, and Roux (2019) argue that the perceived mutability of the resource discrepancy -- defined as the perceived ability for the situation to be changed by investing effort -- influences the route pursued by the consumer. When perceived mutability is high, consumers believe that a reduction of the resource discrepancy is feasible, and worth the effort required to do so. In such situations, consumers pursue scarcity-reduction. In contrast, when perceived mutability is low, consumers believe that they cannot reduce the resource discrepancy, and/or the effort required is disproportionate to the reward. Low-literate, low-income consumers may perceive low mutability in most situations, more likely, therefore, to compensate in domains other than ones with scarcity. They may consumer food heavy in calories (Laran and Salerno 2013) or engage in creative thinking (Mehta and Zhu 2016) to compensate for lack of resources. Consistent with our findings that scarcity triggers concrete (instead of abstract) thinking (Viswanathan et al. 2005; 2018), it appears that scarcity leads to diminished "bandwidth" (ability to hold information in the forefront of consciousness) and "tunneling" (an inordinate focus on the most pressing problem or issue and a neglect of others). Mullainathan and Shafir (2013) show that scarcity results in temporary cognitive impairment that makes people focus on the immediate pressures of scarcity at the expense of long-range planning. Scarcity becomes a causal loop...scarcity breeds scarcity. Furthermore, cognitive functioning necessary for all other decisions, where scarcity is not a factor, is compromised. Additionally, intertwined with the cognitive is the affective as well, and the interplay between the two remains largely unresearched. As noted, our approach has unpacked the cognitive and affective scarcities that underlie observations of tunneling and narrowing, and placed these characteristics in a richer theorization of the nature of thinking and feeling. We have done so by examining broad life circumstances including the role of associated low literacy. 


\section{General Discussion}

We juxtapose our experience with subsistence marketplaces to suggest pathways for research on scarcity. These contexts are characterized by uncertainty in day-to-day consumption and the lack of margin of error overlaying a confluence of extreme resource scarcity and other scarcities. Scarcities here are extreme and different types of scarcities cooccur - resource scarcity and product scarcity, as well as intangible scarcities relating to the cognitive and the affective. Our approach of examining extreme scarcities as they cooccur complements scarcity research, which has isolated discrete types of scarcities and examined moderators and outcomes. Complementing the study of isolated constructs and building theory top-down, a bottom-up exploration of extreme scarcity is valuable for theory development. What happens with extreme and chronic scarcities of multiple types has bearing on understanding different variables and their interactions. What happens at the extremes in the severe lack of many things can inform the moderate lack of one or a few things. Such an approach also addresses the confoundment of levels of a construct with the construct itself. Our approach has the promise of examining the full range of continua for a variety of tangible and intangible types of scarcities.

While in no way comparing the harsh realities of a confluence of resource scarcities to scarcity faced in middle or higher income lives, juxtapositions are instructive. For instance, consumer research on scarcity has focused on the temporal dimension (Hamilton et al. 2019). The nature of the "survival mentality" under time pressure in day-to-day life and as consumers has some similarities, however small, with the pervasive survival mentality in subsistence marketplaces. Situational low literacy due to English as second language mimics cognitive scarcity among those with lower levels of literacy in some ways as does affective scarcity due to self-esteem being involved (Viswanathan et al. 2008), despite such consumers being literate in 
more than language. Examining extreme scarcity on some dimensions can shed light on scarcity in general. Moreover, there are possible differences within even extreme resource scarcity on the cooccurrence of intangible cognitive or affective scarcities.

How does resource scarcity combine with thinking constraints? In some ways, it accentuates the immediate or the here and now, narrowing horizons in terms of spatial, social or temporal. Thus, focusing on a single dimension such as price and buying the cheapest can occur due to low income, low literacy or both. In fact, a differentiating factor here can be the social or relational, as learning from others in a 1-1 interactional world can engender development of consumer skills. Here, we have contrasted ironic advantages in contexts of more widespread poverty when compared to advanced economies where the social milieu blurs with the marketplace. The latter is likely to have a social ecosystem where consumers learn from each other and from small sellers rather than deal with large entities, technology that computes, and an informational environment that assumes the ability to read nutritional labels and other written information.

A case could be made for distinguishing financial and material resources from intangible forms (e.g., social, cultural, cognitive, affective). Furthermore, even within resource scarcity, different sub-categories can be identified and studied separately. For instance, financial resources are most fungible and moved around across domains such as family, consumer and supplier (Viswanathan et al. 2010). Thus, this area of research is fertile for further taxonomical development and subsistence marketplaces provide an ideal context to stimulate thinking.

\section{Conclusion}

Although previous research has examined scarcity in various forms (e.g., product scarcity, resource scarcity, time scarcity), much of it has focused on transient scarcity, with 
limited insights on extreme and chronic resource scarcity, such as in subsistence marketplaces.

Our learning experiences begin with poverty simulations, wherein we ask participants to consider what they did, how they felt, and what the learned about poverty. Participants are consistently surprised by how their thinking was affected and how anxious they felt, and how the latter affected the former and vice versa and led to poor decision-making and loss of resources, even in a simulation. Indeed, scarcities can be of multiple types and to different degrees and what we take for granted is not only the material or the resource abundance, but the cognitive and affective as well, i.e., the thinking and feeling realms. In our research, we have been struck by the uncertainty faced by these consumers in different realms of life as well as their lack of margin of error. Moreover, these consumers face difficulties in abstraction which often lead to sub-optimal choices in the marketplace. There is much to learn from consumers who are not only material survivors but cognitive survivors as well. In conclusion, holistic understanding of extreme scarcity and its multiple dimension from the perspective of consumer behavior can stimulate much future research on scarcity. We unpack cognitive and affective scarcities that add to understanding of poverty in terms of tunneling and narrowing, through rich theorization of the nature of thinking and feeling, examining broad life circumstances including the role of associated low literacy. In so doing, we provide unique insights on how chronic and extreme scarcity influence cognition, emotions, and behavior. 


\section{References}

Alwitt, Linda F., and Thomas Donley, The Low-income Consumer: Adjusting the Balance of Exchange, Sage Publications, Inc, 1996.

Baumeister, Roy F., and Mark R. Leary (1995), “The Need to Belong: Desire for Interpersonal Attachments as a Fundamental Human Motivation," Psychological Bulletin, 117 (3), 497.

Blocker, Christopher P., Julie A. Ruth, Srinivas Sridharan, Colin Beckwith, Ahmet Ekici, Martina Goudie-Hutton, José Antonio Rosa, et al. (2013), “Understanding Poverty and Promoting Poverty Alleviation Through Transformative Consumer Research,” Journal of Business Research, 66 (8), 1195-1202.

Briers, Barbara, and Sandra Laporte (2013), “A Wallet Full of Calories: The Effect of Financial Dissatisfaction on the Desire for Food Energy," Journal of Marketing Research, 50 (6), 767-781.

Cannon, Christopher, Kelly Goldsmith, and Caroline Roux (2019), “A Self- regulatory Model of Resource Scarcity," Journal of Consumer Psychology, 29 (1), 104-127.

Förster, Jens, Ronald S. Friedman, and Nira Liberman (2004), “Temporal Construal Effects on Abstract and Concrete Thinking: Consequences for Insight and Creative Cognition,” Journal of Personality and Social Psychology, 87 (2), 177.

Fortney, John, and Brenda M. Booth (2002), “Access to Substance Abuse Services in Rural Areas," in Alcoholism. Recent Developments in Alcoholism (Services Research in the Era of Managed Care), vol 15. Springer, Boston, MA.

Griskevicius, Vladas, Joshua M. Ackerman, Stephanie M. Cantú, Andrew W. Delton, Theresa E. Robertson, Jeffry A. Simpson, Melissa Emery Thompson, and Joshua M. Tybur (2013), 
"When the Economy Falters, Do People Spend or Save? Responses to Resource Scarcity

Depend on Childhood Environments," Psychological Science, 24 (2), 197-205.

Hamilton, Rebecca, Debora Thompson, Sterling Bone, Lan Nguyen Chaplin, Vladas

Griskevicius, Kelly Goldsmith, Ronald Hill, Deborah Roedder John, Chiraag Mittal,

Thomas O’Guinn, Paul Piff, Caroline Roux, Anuj Shah, and Meng Zhu (2019), “The

Effects of Scarcity on Consumer Decision Journeys," Journal of the Academy of

Marketing Science, 47 (3), 532-550.

Hill, R. P. (2001). Surviving in a Material World: The Lived Experience of People in Poverty, Notre Dame: University of Notre Dame Press.

Lalwani, Ashok K. and Jessie J. Wang (2019), 'How Do Consumers' Cultural Backgrounds and Values Influence Their Coupon Proneness?: A Multi-method Investigation,” Journal of Consumer Research, 45(5), 1037-1050.

Lalwani, Ashok K., and Lura Forcum (2016), “Does a Dollar Get You a Dollar's Worth of Merchandise? The Impact of Power Distance Belief on Price-Quality Judgments,” Journal of Consumer Research, 43 (2), 317-333.

Lalwani, Ashok K., and Kent B. Monroe (2005), “A Re-examination of Frequency-Depth Effects in Consumer Price Judgments," Journal of Consumer Research, 32 (3), 480-485.

Lalwani, Ashok K., and Sharon Shavitt (2009), “The 'Me’ I Claim to Be: Cultural Self-construal Elicits Self-presentational Goal Pursuit," Journal of Personality and Social Psychology, 97 (1), 88-102.

Lalwani, Ashok K., and Sharon Shavitt (2013), "You Get What You Pay For?: Self-construal Influences Price-Quality Judgments," Journal of Consumer Research, 40 (2), 255-267. 
Laran, Juliano, and Anthony Salerno (2013), "Life-history Strategy, Food Choice, and Caloric Consumption," Psychological Science, 24 (2), 167-173.

Luria, Aleksandr R. (1931), "Psychological Expedition to Central Asia,” Science, 74, 383-384.

Martin, Kelly D., and Ronald Paul Hill (2011), "Life Satisfaction, Self-determination, and Consumption Adequacy at the Bottom of the Pyramid," Journal of Consumer Research, $38(6), 1155-1168$.

Mittal, Chiraag, and Vladas Griskevicius (2014), "Sense of Control under Uncertainty Depends on People's Childhood Environment: A Life History Theory Approach,” Journal of Personality and Social Psychology, 107 (4), 621-637.

Mullainathan, Sendhil, and Eldar Shafir (2013), Scarcity: Why Having Too Little Means So Much, Macmillan.

Park, Hanyong, Ashok K. Lalwani, and David Silvera (2020), “The Impact of Resource Scarcity on Price-Quality Judgments," Journal of Consumer Research, forthcoming.

Piff, P. K., M. W. Kraus, S. Côté, B. H. Cheng, and D. Keltner (2010), “Having Less, Giving More: The Influence of Social Class on Prosocial Behavior,” Journal of Personality and Social Psychology, 99, 771-784.

Piff, P. K., D. M. Stancato, S. Côté, R. Mendoza-Denton, and D. Keltner (2012), "Higher Social Class Predicts Increased Unethical Behavior," Proceedings of the National Academy of Sciences, 109, 4086-4091.

Pitta, Dennis, Saroja Subrahmanyan, and J. Tomas Gomez- Arias (2008), “Integrated Approach to Understanding Consumer Behavior at Bottom of Pyramid," Journal of Consumer Marketing, 25 (7), 402-412.

Rosa, J. A., S. Geiger-Oneto, and A. B. Fajardo (2012). "Hope and Innovativeness: 
Transformative Factors for Subsistence Consumer-Merchants," in Transformative Consumer Research for Personal and Collective Well-Being, David, Glen M., Simone Pettigrew, Cornelia Pechmann and Julie L. Ozanne, Editors, New York, NY: Routledge, 151-170.

Shah, A. K., E. Shafir, and S. Mullainathan (2015), “Scarcity Frames Value,” Psychological Science, 26, 402-412.

Sharkey, Joseph R. (2009), "Measuring Potential Access to Food Stores and Food-service Places in Rural Areas in the US," American Journal of Preventive Medicine, 36 (4), S151-S155. Sharma, Eesha, Nina Mazar, Adam L. Alter, and Dan Ariely (2014), "Financial Deprivation Selectively Shifts Moral Standards and Compromises Moral Decisions," Organizational Behavior and Human Decision Processes, 123 (2), 90-100.

Trope, Yaacov, and Nira Liberman (2010), “Construal-level Theory of Psychological Distance," Psychological Review, 117 (2), 440.

Venugopal, Srinivas, Madhubalan Viswanathan, and Kiju Jung (2015), “Consumption Constraints and Entrepreneurial Intentions in Subsistence Marketplaces," Journal of Public Policy \& Marketing, 34.2, 235-251.

Viswanathan, Madhu (2011), "Consumer Behavior Across Literacy and Resource Barriers,” in Wiley International Encyclopedia of Marketing, Volume 3 - Consumer Behavior," Richard Bagozzi and Ayalla A. Ruvio, Volume Editors, Jagdish N. Sheth and Naresh K. Malhotra, Editors in Chief, 44-54.

Viswanathan, Madhu (2012), “Conducting Transformative Consumer Research Lessons Learned in Moving From Basic Research to Transformative Impact in Subsistence Marketplaces," in Transformative Consumer Research for Personal and Collective Well- 
Being, Editors, David Glen Mick, Simone Pettigrew, Cornelia Pechmann, and Julie Ozanne, Routledge/Taylor \& Francis, 107-128.

Viswanathan, Madhubalan (2013), Subsistence Marketplaces, eBookpartnership, eText, and Stipes Publishing.

Viswanathan, Madhubalan (2016), Bottom-Up Enterprise: Insights from Subsistence

Marketplaces, eBookpartnership, eText, and Stipes Publishing.

Viswanathan, Madhu (2017), "Subsistence Marketplaces at the Confluence of Culture, Poverty and Low Literacy: Materially Poor but Relationally Rich?" in Cross Cultural Issues in Consumer Science and Consumer Psychology: Current Perspectives and Future

Directions, van Herk, Hester, Torelli, Carlos (Eds.), Springer, 149-168.

Viswanathan, Madhu, Ronald Duncan, Maria Grigortsuk, and Arun Sreekumar (2018), “A Bottom-up Approach to Understanding Low-income Patients: Implications for HealthRelated Policy." The Journal of Law, Medicine \& Ethics, 46 (3), 658-664.

Viswanathan, Madhubalan, S. Gajendiran, and R. Venkatesan (2008), Enabling Consumer and Entrepreneurial Literacy in Subsistence Marketplaces, Dordrecht: Springer.

Viswanathan, Madhu, Kiju Jung, Srinivas Venugopal, Ishva Minefee, and In Woo Jung (2014), "Subsistence and Sustainability: From Micro-level Behavioral Insights to Macro Level Implications on Consumption and the Environment," Journal of Macromarketing, 34 (1) $8-27$.

Viswanathan, Madhubalan, and Jose Rosa, (2007), "Product and Market Development for Subsistence Marketplaces: Consumption and Entrepreneurship Beyond Literacy and Resource Barriers," in Product and Market Development for Subsistence Marketplaces: Consumption and Entrepreneurship Beyond Literacy and Resource 
Barriers, Jose Rosa and Madhu Viswanathan, Editors, Advances in International Management Series, Joseph Cheng and Michael Hitt, Series Editors, Elsevier, 1-17. Viswanathan, Madhubalan, Jose Antonio Rosa, and James Harris (2005), “Decision-making and Coping by Functionally Illiterate Consumers and Some Implications for Marketing Management," Journal of Marketing, 69 (1), 15-31.

Viswanathan, Madhubalan, Jose Antonio Rosa, and Julie Ruth (2010), "Exchanges in Marketing Systems: The Case of Subsistence Consumer Merchants in Chennai, India," Journal of Marketing, 74 (May), 1-18.

Viswanathan, Madhubalan, Anju Seth, Roland Gau, and Avinish Chaturvedi (2009), “Internalizing Social Good Into Business Processes in Subsistence Marketplaces: The Sustainable Market Orientation," Journal of Macromarketing, 29, 406-425.

Viswanathan, Madhubalan, Srinivas Sridharan, Robin Ritchie, Srinivas Venugopal, and Kiju Jung (2012), “Marketing Interactions in Subsistence Marketplaces: A Bottom-up Approach to Designing Public Policy," Journal of Public Policy and Marketing, 31 (2), $159-177$.

Viswanathan, Madhubalan, Lan Xia, Carlos Torelli, and Roland Gau (2009), "Literacy and Consumer Memory," Journal of Consumer Psychology, 19, 389-402.

Wu, L., and C. Lee (2016), “Limited Edition for Me and Best Seller for You: The Impact of Scarcity Versus Popularity Cues on Self Vs. Other-Purchase Behavior,” Journal of Retailing, 92, 486-499. 
Figure 1: Sampling of Scarcity Research and Selected Distinctions in Subsistence Marketplaces

\section{Research}

Figure 2: Scarcity and Subsistence Marketplaces 


\begin{tabular}{|c|c|}
\hline SAMPLING OF SCARCITY RESEARCH & $\begin{array}{c}\text { SELECTED DISTINCTIONS IN SUBSISTENCE } \\
\text { MARKETPLACES RESEARCH }\end{array}$ \\
\hline $\begin{array}{l}\text { Hamilton et al, (2019) - Moderate searcity of products } \\
\text { and a moderate scarcity of resources influence } \\
\text { consumers at various stages of their decision journeys, } \\
\text { from information search, evaluation of alternatives, } \\
\text { choice, and consumption experiences; product and } \\
\text { resource scarcity attract the consumer's attention, } \\
\text { increase the perceived value of the items being } \\
\text { considered and encourage creativity in use. }\end{array}$ & $\begin{array}{l}\text { Extreme resource scarcity leads to a broader "choice" } \\
\text { of buying, making, or foregoing, individuals having } \\
\text { resilience to do the latter; find it - bay it form of } \\
\text { decision process in light of considerable effort } \\
\text { expended in getting to that point; experience-based } \\
\text { rather than information-processing based purchase } \\
\text { decisions. }\end{array}$ \\
\hline $\begin{array}{l}\text { Cannon, Goldsmith, and Roux (2019) - Moderate } \\
\text { scarcity is aversive and certain conditions lead to } \\
\text { scarcity reduction vs, control restoration; when } \\
\text { perceived mutability - defined as the perceived ability } \\
\text { for the situation to be changed by investing effort - is } \\
\text { high, consumers believe that a reduction of the resource } \\
\text { discrepancy is feasible, and worth the effort required to } \\
\text { do so, and they pursue scarcity-reduction; when } \\
\text { pereeived mutability is low, consumers believe that } \\
\text { they eannot reduce the resource discrepancy, and/or the } \\
\text { effort required is disproportionate to the reward, and } \\
\text { pursue control restoration. }\end{array}$ & $\begin{array}{l}\text { Cognitive survivors rather than cognitive misers; flat } \\
\text { causal inferences; higher levels of abstraction relating } \\
\text { to metacognition and deciding how to decide are even } \\
\text { more difficult to process; lack of control likely a } \\
\text { chronic state as well. }\end{array}$ \\
\hline $\begin{array}{l}\text { Mullainathan and Shafir (2013)- (Moderate levels of) } \\
\text { scarcity results in temporary cognitive impairment and } \\
\text { increases a tunnel vision - to focus single-mindedly on } \\
\text { the scarcity at hand. }\end{array}$ & $\begin{array}{l}\text { Unpacked the cognitive and affective scarcities that } \\
\text { underlie observations of tunneling and narrowing, and } \\
\text { placed these characteristics in a richer theorization of } \\
\text { the nature of thinking and feeling: unpacked material } \\
\text { poverty from cognitive, affective, and behavioral } \\
\text { constraints as well as relational or social richness; } \\
\text { examined affective, behavioral and social facets, } \\
\text { providing basis for deeper exploration of interplay } \\
\text { with cognitive. }\end{array}$ \\
\hline $\begin{array}{l}\text { Park et al, (2019) - Transient scarcity is an aversive } \\
\text { state that people are motivated to reduce; as a result, } \\
\text { people in a moderate scarcity mindset have a desire for } \\
\text { abundance. }\end{array}$ & $\begin{array}{l}\text { With extreme and chronic scarcity, the drive to } \\
\text { survive and subsist appears central rather than a } \\
\text { desire for abundance; the latter may be a luxury } \\
\text { beyond the realm of possibility. }\end{array}$ \\
\hline $\begin{array}{l}\text { Piff et al, ( } 2010) \text { suggest that consumers low in social } \\
\text { class enjoy relational abundance (which increases their } \\
\text { prosocial behavior). }\end{array}$ & $\begin{array}{l}\text { 1-1 interactional marketplace with relational or } \\
\text { social richness; aspects such as interactional } \\
\text { empathy are consistent with prosocial behavior; } \\
\text { however, double-edged as well in how such } \\
\text { relationships can be used to exploit (e.g., cheat due } \\
\text { to low literacy and abuse trust; ostracize for not } \\
\text { adhering to tradition; humiliate for not repaying } \\
\text { loans). }\end{array}$ \\
\hline
\end{tabular}




\section{SCARCITY AND SUBSISTENCE MARKETPLACES}

\section{Characteristics}

- Uncertainty in day-to-day consumption

- Low margin of error

\section{Tangible scarcities}

- Extreme resource scarcity

- Product scarcity

Intangible scarcities

- Cognitive

- Affective

\section{Intangible abundance}

- Relational richness

\section{Consequences for Consumers}

- Concrete thinking

- Difficulty with concepts

- Difficulty combining pieces of information

- Flat causality

- Deciding how to decide

- Cognitive survival

- Pictographic thinking

- Visualizing brand names

- Pattern matching text and numbers

- Visualizing amounts to buy

- Pictographic computing

- Lack of self-esteem and self-confidence in the marketplace

- Behavioral coping strategies

- Problem focused

- Emotion focused

- 1-1 interactional marketplace

- Development of consumer skilts

- Relationship-building

- "Choice" of make or buy or forego

- Importance of marketplace literacy

- Functional literacy in the marketplace

- Cognitive and affective aspects

\section{Future Research}

Information processing and initial evaluation of alternatives

- Types of motivation and types and levels of scarcities

- Interplay between tangible and intangible scarcities

- Moderating effects of literacy and marketplace literacy

- Interplay between scarcities and relationships

\section{Evaluation of alternatives}

- Moderating effects of literacy and marketplace literacy

- Mediating roles of cognitive and affective scarcities

- Types of attributes and scarcities

\section{Choice}

- Types and levels of scarcities and risk perceptions

- Types and levels of scarcities and immediate gratification

\section{Consumption Experience}

- Make or buy or forego decisions

- Consumption experience and levels and types of scarcities

\section{Consumer journey}

- Pre information processing phase

- Blurring of stages and carryover in extreme scarcity

- Scarcities and meta-decision making

\section{Method}

- Bottom-up approach

- Symbiotic academic-social enterprise

\section{Other topics}

- Taxanomy of scarcities

- Subtypes of resource scarcity

- Periodic scarcity 